\title{
Videoclipe: da canção popular à imagem-música ${ }^{1}$
}

\author{
Marcelo Bergamin Conter ${ }^{2}$ (UNISINOS) \\ Suzana Kilpp ${ }^{3}$ (UNISINOS)
}

\section{Resumo}

O presente artigo aborda duas temáticas do videoclipe: uma delas é sua recente autonomização dos modelos de produção e distribuição da indústria fonográfica, causados pela expansão da produção videográfica para a internet. A outra temática trata dos seus devires audiovisuais, aquilo que está congelado na matéria como potência, podendo ou não se atualizar em novos videoclipes, especializando, assim, sua linguagem. Entender a autonomização só é possível compreendendo esses devires, e, para isso, tomamos como referencial teórico pensadores que trataram de temas como tempo, percepção e memória, e os que trataram de audiovisual e música em sua perspectiva técnica, estética e filosófica. Também trata de esclarecer alguns aspectos da canção popular e da história do videoclipe, e de como imagem e música nele se articulam.

Palavras-chaves: Videoclipe; canção popular; devires audiovisuais; imagem-música.

\begin{abstract}
The present article discusses two aspects of videoclip: the first one is its recent autonomization from the phonographic industry production and distribution process, occasioned by the expansion of internet videos productions. The other topic is about its audiovisuals devenirs, which is what is freezed on the substance as potency, and it may or not actualize itself on newer videoclips, specializing its language. It is only possible to understand the autonomization understanding these devenirs, and, to do so, we take as theoretical reference authors that deals with subjects such as time, perception and memory, and others that which the main focus is the technical, esthetical and philosophical field of audiovisual and music. This article also brings new perspectives to some aspects of popular song and videoclip history, and how image and music articulates each other on it.
\end{abstract}

Keywords: Videoclip; popular song; audiovisual devenirs; music-image. 
Como pretendemos estudar as articulações da música com a imagem em videoclipes, cabe inicialmente uma breve introdução ao que estamos chamando neste artigo de canção popular, pois o videoclipe, que se populariza nos anos sessenta junto com o rock, incorpora desse estilo musical - e de outros que dele derivam as estruturas ${ }^{4}$ que o caracterizam como tal.

O rock, nos Estados Unidos, aparece em meados dos anos cinqüenta e se desenvolve a partir da mistura do blues com o country e o jazz. Entre os grandes nomes dessa primeira fase, Elvis Presley, que produziu uma série de filmes musicais, como Jailhouse Rock (Richard Thorpe, 1957). Na época, o estilo era constituído basicamente de baladas e músicas dançantes. Mas na segunda metade dos anos sessenta, já consolidado mundialmente, o estilo começa a criar raízes das mais diversas. Esse processo desenvolve-se em paralelo com a viagem dos Beatles para a Índia. Drogas, mega-festivais hippies como Woodstock, e a influência da cultura oriental começam a tensionar o rock. Surgem vertentes das mais variadas: rock psicodélico, progressivo, heavy metal, e assim por diante.

Durante os anos setenta, após a onda do progressivo e do metal, que eram estilos cujas canções eram dotadas de complexidade e extensividade maiores, aparece o punk rock, com músicas curtas, às vezes com apenas um minuto, e com estruturas muito simplificadas. Em paralelo, crescia também a dance music dos Bee Gees. A mistura de ambos com a música eletrônica resultou no pop dos anos oitenta, que foi impulsionado pela MTV (Music Television). A partir daí o pop e o rock começam a se confundir e a produzir subgêneros e novas misturas. Technopop, eurodance, pós-punk, metal melódico e hard core são apenas algumas das várias terminologias que surgiram entre os anos 80 e 90 para designar a multiplicidade de categorias musicais que não pararam de ser inventadas.

De qualquer forma, se nos concentramos em encontrar uma média de todos estes estilos que compõem o que entenderemos aqui por canção popular, iremos perceber que as canções de todos os estilos citados possuem certas tendências, especialmente as que seguem:

- Apelo popular e midiático;

- Peças curtas;

- Letras de fácil memorização;

- Estrutura simplificada e cíclica: estruturas como um trecho a $b$ a $b$ (ex: verso - refrão - verso - refrão)

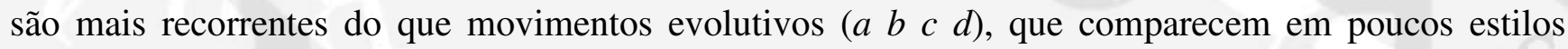
populares, como o rock progressivo;

- Repetição: ocorre das mais diversas maneiras - a repetição do refrão, de um verso, de um motivo musical, de uma batida ${ }^{5}$, de um trecho qualquer. A melodia também é repetida freqüentemente, não só 
no refrão, mas as frases dos versos tendem a ser sempre em cima de uma melodia que se repete, mudando apenas a letra.

A canção popular encontra no videoclipe um lugar diferenciado para se territorializar. Como poderemos perceber a seguir, foi a partir dele que a canção popular entrou nas mídias audiovisuais. Não só na televisão, mas também no home video, cinema, internet, entre outros, porque é natural o videoclipe transitar entre mídias e ser também suporte delas. Por isso, não é à toa que o videoclipe desenvolveu-se como meio de experimentação, de inovação e de novas propostas audiovisuais, abrindo caminho para diretores de fotografia, cinema, vídeo arte e TV realizarem trabalhos diferenciados.

Ainda que o videoclipe comece a tomar forma ${ }^{6}$ nos anos 60 , é importante lembrar que há devires seus em audiovisuais anteriores, como o cinema.

Por exemplo, entre a década de 50 e 60, como podemos constatar nos filmes do Elvis Presley e dos Beatles, os musicais começaram a reduzir a importância do enredo em função das músicas performizadas inseridas. Trechos musicais podiam ser clipados (recortados do contexto original) e apresentados independentemente. Como ainda não eram pensados para, nem produzidos em vídeo, não podemos chamá-los propriamente de videoclipe. Chamaremos aqui então estes trechos, bem como outros modos de produção audiovisual musical pré-vídeo, de peças musicais, que seriam, então, devires de videoclipe.

As peças musicais só passaram a ser produzidas com um direcionamento publicitário, visando à divulgação de uma música e de um músico, a partir dos anos 60, especialmente a partir dos Beatles. Ainda se capturava em película; no entanto, essas peças eram convertidas (telecinadas) em vídeo para serem exibidas na televisão. Algumas tendências que hoje são recorrentes já começavam a aparecer: no clipe Strawberry Fields Forever (1967), por exemplo, dirigido por Peter Goldmann para música dos Beatles e produzido em película (frame 1), deu-se preferência a imagens arbitrárias, descontínuas, a efeitos de iluminação etc., em detrimento da necessidade do playback ${ }^{7}$, de ver os músicos necessariamente tocando e cantando.



Frame 1 
Desde seus primórdios, então, conforme Machado (1995: 170), podemos pensar que o videoclipe “[...] pode dispensar inteiramente o suporte narrativo e o seu público já está preparado para aceitar imagens sem nenhum significado imediato, sem qualquer denotação direta, sem referência alguma no sentido fotográfico do termo, desde que o seu movimento seja harmônico com o da música”.

Entre os anos sessenta e setenta havia vários programas de TV que exibiam videoclipes em sua programação. Em 1975, surge um dos mais relevantes videoclipes da história: Bohemian Rapsody, dirigido por Bruce Gowers para música do Queen. Mesmo tendo sido produzido com um orçamento baixo, a sua edição é impecável, buscando representações visuais para os arranjos sonoros, utilizando efeitos de vídeo (como o feedback ${ }^{8}$ apresentado no frame 2) que o transformaram em referência.

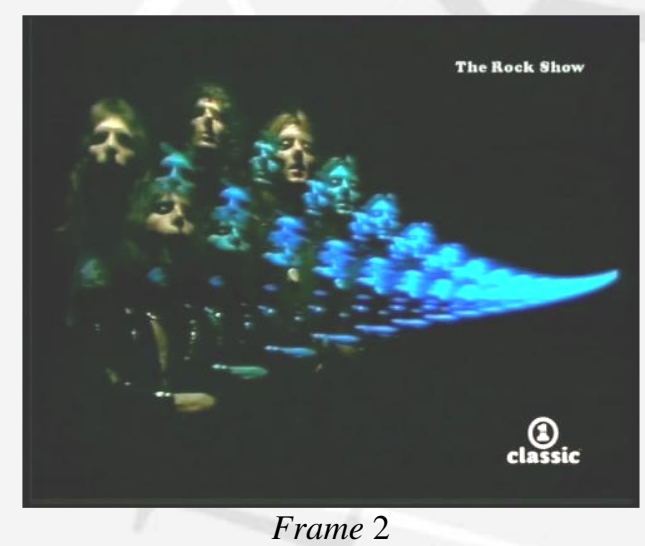

Começa então a parecer essencial para todos os músicos e bandas que se produzam clipes de suas músicas de trabalho, e, como a produção aumenta, parece se fazer necessário um novo espaço na televisão para os clipes musicais.

Nos anos 80 o videoclipe encontra um lugar privilegiado na televisão: a MTV. Como já havia uma produção expressiva de videoclipes, o canal surge com a promessa de transmitir uma programação onde eles seriam a base fundamental. Com uma grade constituída quase que inteiramente de comerciais (afinal, a indústria fonográfica paga para ter seus vídeos exibidos), transmissão 24 horas diárias e se instalando em diversos países, seria de se esperar que, em paralelo ao fenômeno MTV, a produção de videoclipes atingisse escala industrial. E foi o que ocorreu. A MTV

“[...] alterou profundamente certas concepções de fazer e ver TV e [...] conseguiu detectar e reforçar certos traços ou estilos da contemporaneidade [...]. Um desses traços é o da presença, junto à imagem, do som. Não apenas o som, mas o som musical. A música. E não a música-pano de fundo, mas a música como constituinte essencial da imagem". (COELHO NETTO, 1995:159-160)

Foi especialmente nessa fase que a linguagem do videoclipe se desenvolveu com mais velocidade. Se, num dado momento, os clipes basicamente exibiam os músicos performizando em playback e contavam 
historietas relacionadas à letra da canção, nos anos 80 isto se desdobrou, chegando até vídeos como Thriller (1982), de John Landis para música do Michael Jackson, com treze minutos de duração, misturando linguagem cinematográfica e assemelhando-se a um filme. Outra característica de Thriller são os intervalos com diálogos e sem música: a canção começa efetivamente após quatro minutos de sequiências cinematográficas de diálogos, sendo que ainda é editada diversas vezes ao longo do clipe. No caso, não só se tensionou os limites entre mídias audiovisuais (cinema, televisão e videoclipe), como também o videoclipe expandiu-se para o mercado do home video, tendo sido o VHS de Thriller um sucesso de vendas.

Enquanto a MTV usava e abusava de cromaquis ${ }^{9}$ em seus programas, os diretores de videoclipe também se apropriavam da tecnologia, e a convergência de formatos passa a ser praticada com mais destreza, como no clipe Opportunities (1986, frame 3), dirigido por Zbigniew Rybczynski para música de Pet Shop Boys.

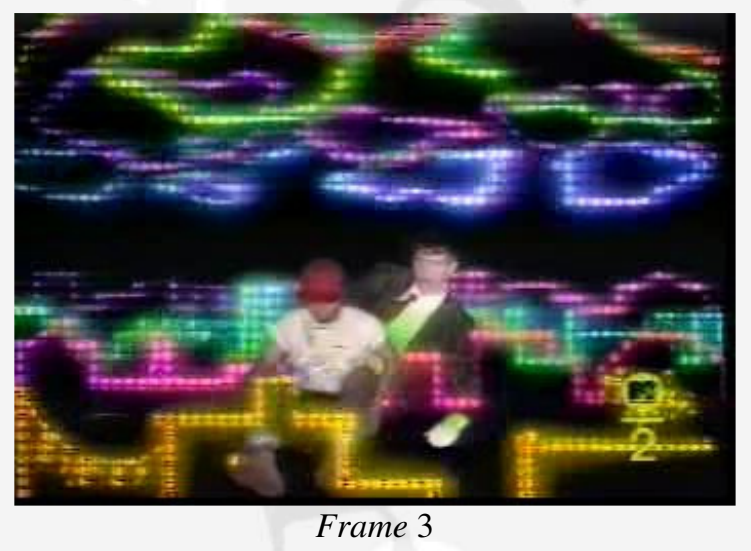

Nos anos noventa, a tecnologia facilitou montagens mais vertiginosas, trabalhando com planos mais rápidos e imagens mais impactantes. Os planos são medidos não mais por segundo, mas por frações de segundo, às vezes mais rápido até que a batida da música. Isso parece ter ocorrido em simultâneo com o surgimento do grunge, uma espécie de pós-punk, com timbres sujos, vocais gritados e sonoridades densas, que nasceu no underground americano, e inverteu as paradas de sucesso, passando por cima até de nomes como Madonna e Michael Jackson. Seu representante-mor é a banda Nirvana, justamente a que causou tal inversão, com seu vídeo Smells Like Teen Spirit (1991), dirigido por Samuel Bayer, ao qual se refere o Frame 4. 


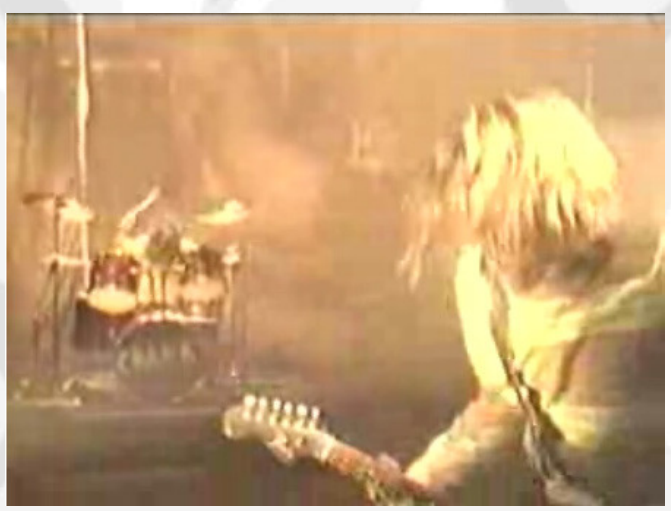

Frame 4

Como diz Machado (2001: 177), “o que vale agora é a energia que se imprime ao fluxo audiovisual, a fúria desconstrutiva e libidinosa que sacode e dissolve as formas bem definidas impostas pelo aparato técnico. [...] agora presenciamos o retorno a um primitivismo deliberado, à imagem "suja", mal iluminada, mal ajustada, mal focada e granulada, o corte, a rebarba, a câmera sem estabilidade e sacudida por verdadeiros terremotos, todas as regras mandadas para o vinagre e todo o visível reduzido a manchas disformes, deselegantes, gritantes, inquietantes".

Foi comum nos anos noventa este tipo de composição, e não apenas quando se tratava de grunge. Aliás, o videoclipe absorveu alucinadamente os mais variados efeitos técnicos e de montagem. Ainda que haja clipes em plano-seqüência, ou com transições suaves, elementos que se contrapõem à estética da montagem vertiginosa, esta sempre se encontra presente no videoclipe, ao menos como potência, desde os noventa, pelo fato de o videoclipe ser um lugar de passagem: ele é cinema $e$ tevê $e$ foto $e$ animação $e$ pintura $e t$ cetera.

"O vídeo ${ }^{10}$ assimila todas as outras imagens, permite a conexão entre os suportes, a transição entre pintura, fotografia e cinema. Na medida em que é uma mídia capaz de integrar e transformar todos os outros, o vídeo é o lugar por excelência de passagem: tudo passa na televisão. Para onde vai o vídeo? Para todo o lado, em todas as direções. [N.R.: Jean-Paul Fargier, "Les elétrons ont la vie dure", em Où va la video? (Paris: Éditions Cahiers du Cinéma, 1986), p.7.]”(PEIXOTO, 2004: 241)

O fato de o videoclipe ser composto e atravessado por imagens de diferentes naturezas e a partir dos mais diversos suportes, caracteriza-o como heterotópico e heterocrônico, que são conceitos de Michel Foucault assim traduzidos por Rezende (2000: 254): “[...] as heterotopias são espaços que "têm a curiosa propriedade de estar em contato com todos os outros" espaços e, onde "todos os outros locais (emplacements) reais que se podem encontrar no interior da cultura, estão representados ao mesmo tempo, contestados e invertidos". [...] quando "os homens se encontram em um tipo de ruptura absoluta com seu tempo tradicional", isto é, uma dada heterotopia se liga a uma heterocronia correspondente. [...] as heterotopias guardam ainda um sistema de “"passagem” ou de "entrada e saída” capaz de, ao mesmo tempo, isolá-las e torná-las penetráveis. 
Apesar de ser normalmente pensado para a televisão, como viemos mostrando o videoclipe se territorializa nas mais diversas mídias audiovisuais. Ou seja: não é apenas em si que ele é heterotópico e heterocrônico, mas também na sua passagem, entrada e saída das mais diversas mídias. Ele transita em todas e entre elas.

Assim como ele deslocou-se do cinema (como peças musicais produzidas em película) à TV, e transita por tantas mídias e suportes, o clipe chegou, mais recentemente, à internet. Ou seja, o videoclipe não surgiu nem para, nem pela TV. E já surgiu mesclando linguagens diferentes, da televisão, do cinema, e da música. Então ele não seria um gênero televisivo, mas um audiovisual que transcende as mídias. Compreender sua natureza como audiovisual que transcende as mídias pode ajudar a percebermos que suas potencialidades se atualizam nas novas formas de produzir e assistir vídeos (como a internet).

Com a conexão de banda larga, abriu-se espaço para softwares (pagos e gratuitos) de downloads de arquivos, e sites onde se pode pesquisar e assistir a vídeos. Há softwares, como o eMule, que realizam conexões diretas de usuário para usuário (sem o intermédio de um servidor com banco de dados), permitindo a troca e obtenção de arquivos ilegalmente (pois, dessa maneira, o usuário não paga para baixar um arquivo). Os mais populares são os mais rápidos de serem baixados, por serem compartilhados por vários usuários. Baixar clipes pelo eMule foi a maneira mais simples de encontrar, assistir, dissecar e analisar os clipes que estou estudando. Quanto aos sites de vídeo, o mais popular é o YouTube, que estimula a veiculação de vídeos amadores de desconhecidos, muitos dos quais se tornaram as chamadas "febres da internet".

É notável que algumas bandas - especialmente as independentes de gravadoras - vêm publicando seus vídeos em sites como o YouTube e ficando populares a partir disso. Mais curioso ainda é que a estrutura que a internet possui para abrigar vídeos tem revelado trabalhos que não foram concebidos a partir de uma canção. Está disponível, por exemplo, o videoclipe MC Jeremias, remontagem de duas reportagens realizadas por um programa de TV sensacionalista em que o repórter entrevista um jovem embriagado, que responde gritando e praguejando. O realizador, um brasileiro denominado "Viniciux", montou os diálogos da reportagem de forma que se encaixassem com o ritmo de uma batida de funk carioca. Outro exemplo é o videoclipe Amateur, do sueco Lasse Gjertsen. Ele se gravou em vídeo batendo em cada uma das peças de uma bateria individualmente, repetiu isto com as teclas de um piano, e, na montagem do clipe, compôs uma música com os trechos registrados de cada nota tocada em cada instrumento. Os dois clipes não foram produzidos a partir de uma música. Ocorreu exatamente o contrário: a partir do que havia sido registrado em vídeo se concebeu a música, invertendo a lógica habituada do vídeo de clipe, talvez insinuando a emergência de uma espécie de clipe de vídeo.

Casos como estes comprovam que os modos diversos de recepção e interatividade da internet vêm provocando uma reviravolta no que se entendia por videoclipe até o começo dos anos 2000 . O que está 
acontecendo é que os clipes, que antes eram planejados para serem uma espécie de anúncio publicitário, com o intuito de divulgar o álbum musical de um artista, agora estão se autonomizando na rede mundial de computadores, tornando-se um fim em si mesmos. Além disso, ainda há o fato de estarem se criando éticas e estéticas inovadoras, e que não funcionariam na $\mathrm{TV}^{11}$. Essa transição para a web cristaliza a fase televisiva do videoclipe ao mesmo tempo em que dá margem a novas possibilidades, tanto a inovações gramaticais como a devires de videoclipe.

A questão passa a ser, então, o que é o videoclipe? Qual é a memória ou duração videoclipe? O que é devir videoclipe? Para responder a essas questões invocamos esses conceitos como foram propostos pelo filósofo Henry Bergson. O autor diz que todas as coisas têm dois modos, duas naturezas: no seu modo de ser a natureza da coisa é virtual; no seu modo de agir, a coisa é atualidade. Na natureza virtual há uma prevalência do tempo, da duração, da memória; na natureza atualizada, a duração (como tempo) encontra-se congelada na matéria, na forma, no espaço.

Entretanto, o autor admite a dificuldade de tratar as coisas desses modos, uma vez que o tempo real (o da duração) é inapreensível. Diz ele: "Muito nos impressionou, com efeito, ver como o tempo real, que desempenha o papel principal em toda filosofia da evolução, escapa à matemática. Sua essência consistindo em passar, nenhuma de suas partes está mais aí quando outra se apresenta” (BERGSON, 2006c: 4). Ou: duração é o que nós sempre chamamos de tempo, entretanto, o tempo imperceptível, indivisível, como "[...] progresso contínuo do passado que rói o porvir e incha à medida que avança.” (BERGSON, 2006a: 47). E como esse movimento é incessante, o passado não pára de se atualizar no presente, a memória de se atualizar na matéria, e assim por diante.

Então, o tempo absoluto, ou melhor, a duração bergsoniana, assim como todas as coisas, também possui dois modos: o modo de ser, ou virtual; e o de agir, ou atual. O virtual da duração seria o eterno devir. O atual da duração ocorre sempre que ela encontra matéria, quando se congela. Virtuais e atuais trocam incessantemente de posição na evolução criadora, e contêm-se um ao outro. Assim, todo o passado coexiste no presente, através justamente destes dois modos da duração, pois a memória "faz bola de neve consigo mesmo" (idem, p. 2). Mais adiante, o autor diz: "De fato, não há percepção que não esteja impregnada de lembranças. Aos dados imediatos e presentes de nossos sentidos misturamos milhares de detalhes de nossa experiência passada." (idem, p. 86).

Portanto, nessa perspectiva, podemos pensar o videoclipe em seus dois modos: o de ser (virtual) e o de agir (atualizado). Assim, como já dissemos, o videoclipe não pode ser reduzido a um gênero televisivo, uma vez que passou - e passa - pelas mais diversas mídias audiovisuais. Mas podemos dizer, sim, que o videoclipe na televisão é uma de suas atualizações, assim como ocorre no cinema, na internet, no VHS, entre outros.

Todas as mídias que (per)passam o videoclipe (e pelas quais ele transita) condensam-se numa coexistência virtual, condensando-se em cada clipe a memória de seu desenvolvimento estético, técnico e 
cultural. E é isso que tentamos evidenciar no artigo em pauta, que, conforme Bergson (1999), não existe percepção sem memória, sendo que percepção e lembrança interpenetram-se sempre, trocando entre si algo de suas substâncias, graças a um fenômeno de endosmose. Para o autor, a nossa experiência - a nossa representação - é a mistura dessas duas linhas: a linha que leva a lembrança à percepção e a que leva a percepção à lembrança.

Quando somos afetados por determinado objeto, outras lembranças podem surgir nesse momento, tanto do mesmo objeto quanto lembranças que podem nos ajudar a perceber e a agir a partir dessa afecção, porquanto “[...] perceber consiste em condensar períodos enormes de uma existência infinitamente diluída em alguns momentos mais diferenciados de uma vida mais intensa, e em resumir assim uma história muito longa. Perceber significa imobilizar." (BERGSON, 2006a: 88).

Isso implica em assentir que, para analisar o tempo, é preciso antes espacializá-lo, pois estamos, sem dúvida, retirando o objeto da duração e congelando-o, recuperando aquilo que percebemos dele em nossa memória. Esse ato exige uma mediação que naturalmente transforma o tempo em medidas, em formas.

Seincman (2001) levanta uma questão importante da filosofia bergsoniana. Não é que estejamos errados em espacializar o tempo para nossas análises científicas, pois é assim que percebemos as coisas. Entretanto, é preciso, em seguida, devolver o nosso objeto à duração, para que possamos verificar se o que constatamos de sua natureza se aplica não somente a quando espacializado, mas também quando em seu modo de ser.

O mesmo podemos pensar em relação à canção popular, a qual "imobilizamos” para perceber. Falamos de instantes de música como se fosse algo que de fato ocorresse. Mas o instante é algo que não pode ocorrer na duração a não ser quando congelada. Ao interpretar uma partitura musical, percebe-se que um compasso é composto de várias notas, e cada nota, de várias ondas sonoras. Dividir as ondas de uma só nota até chegarmos a uma onda singular fará com que não reconheçamos mais a música, sequer a nota. Ouviremos apenas um ruído. Devemos acrescentar que som é onda vibratória, por isso em mudança contínua de estado, que não cessa de mudar. Impossível então estacionar na música ${ }^{12}$. Quando algo se dá em fluxo, como a música, implica uma necessária e incessante mudança. E, ainda mais de coisas que aparentam ser imóveis, as coisas especialmente moventes requerem métodos adequados para que se perceba sua duração.

Percebemos como "instantes da música" o que nos interessar para agir no momento em que a ouvimos: memorizar um verso, o refrão cativante, uma melodia, algo que seja assoviável, algo que nos permita acompanhar a canção, enquanto que, por outro lado, sentimos de alguma forma a música variando, fluindo. Conseguimos memorizar trechos, mas nunca essa sensação de fluxo. Essa variação, sensação de mudança que sentimos somente ao ouvir uma canção, à qual no entanto não conseguimos dar forma, é a duração canção na canção atualizada.

Talvez seja esse um dos motivos que faça com que a canção popular opere com tantos intervalos repetidos, facilitando a memorização da peça. São os padrões estruturais, que estão presentes nos mais diversos 
estilos, desde o jazz até o punk rock. Um dos mais simples é este: introdução - primeiro verso - refrão segundo verso - refrão - final. Com maiores ou menores variações, às vezes aparece um solo, às vezes uma ponte antes do refrão. Esse padrão é extremamente recorrente. Ele mexe com nossa memória-hábito: ao ouvirmos um primeiro verso, esperamos ouvir um segundo em seguida, consequiência dos ritmos e compassos divididos e organizados em grupos de quatro, que estão presentes em boa parte das canções populares. Já desconfiamos como a música vai continuar, e assim vamos percebendo-a através de instantes (trechos medidos pela nossa consciência). Num outro extremo, quando somos convidados a ouvir pela primeira vez uma composição eletroacústica, que não costuma seguir padrões rítmicos, ficamos entregues ao fluxo da música e de nossa própria duração, e temos a sensação de "tempo passando" reforçada, perdendo também a sensação ${ }^{13}$ de controle do porvir. Temos esta sensação quando podemos medir as coisas, enquanto que, quanto mais longos e irregulares os intervalos entre instantes, mais fraca ela é.

Assim a ciência também opera, segundo Bergson (2006b: 68): “[...] no que concerne ao tempo a ciência conta instantes, anota simultaneidades, mas continua sem domínio sobre o que se passa nos intervalos. Pode aumentar indefinidamente o número das extremidades, encurtar indefinidamente os intervalos; mas o intervalo sempre lhe escapa, mostra-lhe apenas suas extremidades".

Trata-se de um constante e repetitivo pulso, normalmente regular, previsível: um ritmo. Diz-se arbitrariamente que o ritmo, através de instantes, separa a música em intervalos. Mas, como já tratamos, esse intervalo é abstrato, é uma formalização da música no nosso pensamento, uma maneira de podermos apreender a canção. A música é indivisível, e ela muda de natureza ao se dividir. Por isto, é essencial compreendermos ritmo - e, conseqüentemente, música - como algo que ocorre necessariamente em fluxo. As estruturas musicais são formas que desenvolvemos para poder analisar determinada música.

Como a música acontece somente em fluxo, ela precisa desenvolver meios para destacar os elementos mais importantes de sua estrutura. A retomada de certos trechos dentro do fluxo musical faz com que essas canções sejam facilmente memorizadas. Quando escutamos um trecho que percebemos ser similar a um anterior, não estamos exatamente ouvindo "uma repetição", pois, para nossa percepção, esta vai diferir da primeira audição ${ }^{14}$. Vamos assim expandindo nossa memória, assimilando a canção por contigüidade (coexistência virtual). "A escuta é prenhe de lembranças, impressões imediatas e expectativas que conformam e alteram constantemente o significado do que foi, do que está sendo e do que será. Não pode haver dois fenômenos idênticos, pois o tempo não se repete jamais." (SEINCMAN, 2001: 31)

É essencial que haja repetição para haver música, pois ela nada mais é do que vibrações sonoras organizadas, que repetem incessantemente um movimento pulsante ao vibrarem. Dessa forma, podemos dizer que o virtual da música é o pulso sonoro. O ritmo é uma de suas atualizações, que, por sua vez, também é o virtual de um outro elemento musical: "O bater de um tambor é antes de mais nada um pulso rítmico. Ele emite freqüências que percebemos como recortes de tempo, onde inscreve suas recorrências e suas variações. Mas se 
as freqüências rítmicas foram tocadas por um instrumento capaz de acelerá-las muito, a partir de cerca de dez ciclos por segundo, elas vão mudando de caráter e passam a um outro patamar, o da altura melódica. A partir de um certo limiar de freqüência [...], o ritmo "vira" melodia". (WISNIK, 1999:20)

A melodia, sequiência de notas produzidas num dado intervalo de tempo, é o virtual da harmonia, que é quando escutamos três ou mais notas simultaneamente, formando acordes (mi menor, ré maior...), ou linhas melódicas (polifonia). É a base da canção popular. Acordes, na partitura, ocorrem quando encontramos grupos de notas dispostas verticalmente na pauta, criando então diversas linhas melódicas (eixo horizontal da pauta) simultâneas.

Sob esse ponto de vista, pode-se dizer que a canção popular é dotada de uma série de fluxos simultâneos, que se complementam e competem entre si na duração musical ${ }^{15}$. Cada fluxo desenvolve-se de maneira independente na duração, como se pode perceber ao ler uma linha melódica numa partitura musical, que percorre a pauta horizontalmente. Percebemos sua relação com os outros fluxos devido a uma percepção vertical do avanço simultâneo de diversos fluxos. "Chamamos então simultâneos dois fluxos exteriores que ocupam a mesma duração porque estão ambos compreendidos na duração de um mesmo terceiro, o nosso [...]” (BERGSON, 2006b: 61).

O apogeu do estudo da harmonia na música ocidental se deu no período Barroco, com o contraponto, que se trata da técnica de combinar duas ou mais vozes melódicas, criando tensionamentos verticais ${ }^{16}$, e o seu expoente são as obras de Bach. E foi justamente do contraponto que o cineasta russo Sergei Eisenstein (2002) tira o exemplo de como avançar os estudos sobre montagem cinematográfica. Ele imagina como seria uma partitura áudio-visual, adicionando "um novo item às partes instrumentais: este novo item é uma 'pauta' de imagens visuais, que se sucedem e que correspondem, de acordo com suas próprias leis, ao movimento da música - e vice-versa." (EISENSTEIN, 2002: 54). Com isso, Eisenstein pensa que se poderia criar tensões mais complexas e dramáticas ao se realizar um jogo dialético entre som e imagem, ponto contra ponto. Esse jogo de contrapontos, no entanto, não criará exclusões, mas conjunções: "Estamos acostumados a fazer, quase que automaticamente, uma síntese dedutiva definida e óbvia quando quaisquer objetos isolados são colocados à nossa frente lado a lado.” (EISENSTEIN, 2002: 14). O autor argumenta então que

“[...] teremos de extrair de nossa experiência do cinema mudo um exemplo de montagem polifônica, na qual um plano é ligado ao outro não apenas através de uma indicação - de movimento, valores de iluminação, pausa na exposição do enredo, ou algo semelhante -, mas através de um avanço simultâneo de uma série múltipla de linhas, cada qual mantendo um curso de composição independente e cada qual contribuindo para o curso de composição total da seqüência”. (EISENSTEIN, 2002: 55)

Essa relação de simultaneidade entre os fluxos é típica do audiovisual. Mesmo que determinado videoclipe se utilize de uma música pré-concebida, como é o caso da maioria, sempre estamos diante de uma nova obra singular. "A busca da correspondência deve ocorrer a partir da intenção de combinar quadro e 
música com a 'imagem’ geral, complexa, produzida pelo todo.” (EISENSTEIN, 2002: 56). Quando a canção popular encontra o videoclipe, ela muda de natureza, adquirindo então uma duração audiovisual; porém, mesmo que percebamos os diversos fluxos que compõem o videoclipe, eles não podem ser divididos, separados, sob pena de se mudar sua natureza audiovisual.

A música que ouvimos no clipe difere da que ouvimos no $\mathrm{CD}$, e não somente quando ocorrem acréscimos sonoros, como ruídos e diálogos. Difere especialmente porque agora se trata de audiovisual. Ela faz parte de um código sincrético, que chamaremos aqui de imagem-música, um conceito de Silva (2005: 2): "Imagem-música é um texto sincrético, isto quer dizer, um texto formado por diferentes linguagens em cujos planos de expressão importam mais as articulações entre sons (musicais) e imagens, do que as gramáticas específicas de cada linguagem considerada isoladamente.” Mas é preciso deixar claro que a imagem-música só aparece em modelos computacionais, onde videográficos e ondas sonoras são criados, registrados e reproduzidos através de um mesmo código binário. No videoclipe, encontramos apenas devires de imagemmúsica.

Compreender (e reinventar a pesquisa sobre) o videoclipe a partir de uma perspectiva técnica e estética passa necessariamente por um estudo de seus devires, de suas audiovisualidades, de referencial teórico do audiovisual e também (e tão importante quanto) de teoria musical. É preciso dar conta de como ele se comporta na duração, das articulações que imagem e música produzem contrapontisticamente, e pensá-lo fora da televisão, transcendendo o gênero televisivo, pois, do contrário, estar-se-ia congelando-o numa matéria que não abriga toda a sua memória. 


\section{Referências bibliográficas}

BERGSON, Henri. Matéria e memória. 2. ed. São Paulo: Martins Fontes, 1999.

BERGSON, Henri. Memória e vida. São Paulo: Martins Fontes, 2006a.

BERGSON, Henri. Duração e simultaneidade. São Paulo: Martins Fontes, 2006b.

BERGSON, Henri. O pensamento e o movente. São Paulo: Martins Fontes, 2006c.

CARVALHO, Any Raquel. Contraponto modal: manual prático. Porto Alegre: Evangraf, 2006.

COELHO NETTO, José Teixeira. Moderno pós moderno: Modos \& Versões. São Paulo: Iluminuras, 1995.

EISENSTEIN, Serguei. O sentido do filme. Rio de Janeiro: Jorge Zahar, 2002.

MACHADO, Arlindo. A arte do vídeo. São Paulo: Brasiliense, 1995.

MACHADO, Arlindo. A televisão levada a sério. São Paulo: SENAC, 2001.

PEIXOTO, Nelson Brissac. "Trânsito - vídeo: arquitetura/pintura/cinema”. In: Paisagens Urbanas. $3^{\mathrm{a}}$ ed. São Paulo: Senac, 2004.

REZENDE, Luiz Augusto. "Cinema e televisão - heterotopias e heterocronias". In: SOCINE II e III: Estudos de cinema. São Paulo: Annablume, 2000.

SCHAFER, R. Murray. O ouvido pensante. São Paulo: UNESP, 1991.

SEINCMAN, Eduardo. Do tempo musical. São Paulo: Via Lettera, 2001.

SILVA, Alexandre Rocha da. "Devires de Imagem-Música". In: INTERCOM - XXVIII Congresso Brasileiro de Ciências da Comunicação, 2005, Rio de Janeiro. INTERCOM, 2005. Disponível em: <http://reposcom.portcom.intercom.org.br/dspace/bitstream/1904/16872/1/R0921-1.pdf>. Acesso em: 19 out. 2007.

WISNIK, José Miguel. O som e o sentido: uma outra história das músicas. São Paulo: Companhia das letras, 1999.

\footnotetext{
${ }^{1}$ Este artigo é um recorte do Trabalho de Conclusão de Curso (TCC) de Marcelo Bergamin Conter "Devires audiovisuais e a autonomização do videoclipe”, sob orientação da Profa. Dra. Suzana Kilpp, aprovado em dezembro de 2007.

2 Graduando em Comunicação Social: Hab. Publicidade e Propaganda (UNISINOS). Bolsista PIBIC. bconter@gmail.com

${ }^{3}$ Doutora em Comunicação Social. Programa de Pós-Graduação em Ciências da Comunicação (UNISINOS). sukilp@ unisinos.br

${ }^{4}$ Essas estruturas existem para organizar a canção, tal como os movimentos de uma sinfonia. Um exemplo simples e recorrente na canção popular: "introdução - verso - refrão - verso - refrão - final”.

${ }^{5}$ Chamaremos aqui de batida as unidades de tempo musical que se repetem regularmente.

${ }^{6} \mathrm{O}$ conceito de forma, que é uma espacialização do tempo, será explicitado adiante.

${ }^{7}$ Procedimento técnico em que uma música pré-gravada é aplicada à trilha de áudio, enquanto na trilha da imagem ela é performizada por músicos. É utilizado comumente em videoclipes e em programas televisivos como o Domingo Legal, do SBT.

8 "Em vídeo, é o nome que se dá ao efeito gerado por um circuito fechado onde a câmera é apontada para a tela do mesmo monitor que exibe a imagem que ela capta. O resultado é uma espiral caleidoscópica móvel, que pode ser modificada infinitamente, a partir de qualquer manipulação da câmera.” (MACHADO, 1995: 212)
} 
${ }^{9}$ Traduzido do inglês Chroma Key, este efeito consiste em "interpretar" determinada cor capturada por uma câmera de vídeo como "transparente". É largamente praticado em programas de estúdio, utilizando-se um fundo azul ou verde que se torna transparente na mesa de edição. Se alguém estiver vestindo roupas da cor da parede, ficará invisível também. No caso dos videoclipes, a tendência foi a de utilizar o cromaqui para inserir os artistas em mundos fantasiosos, como é o caso do clipe opportunities, mencionado no texto.

${ }^{10}$ Aqui, Peixoto se refere ao vídeo em geral.

${ }^{11}$ Artistas como a dupla Godley e Creme (vide MACHADO, 2001) já criaram peças (como Mondo Vídeo, de 1989) em cujo processo se tratava de produzir músicas a partir de imagens. Hoje é comum encontrar trabalhos assim na internet, o que ainda não ocorreu efetivamente na televisão.

${ }^{12}$ Murray Schafer trata disso em seu livro $O$ ouvido Pensante quando escreve que o som estacionário "Não existe. No som, tudo está em movimento. Contudo, pode parecer haver, no meio de um som, um período no qual nada muda (a mesma frequiência, o mesmo volume etc.) e, para o 'ouvido nu’, o som parece ser não progressivo e estacionário.” (1991: 181)

13 "Sensação" porque de fato não podemos alterar o desenvolvimento da canção.

${ }^{14} \mathrm{~A}$ sensação mais comum é a de já se ter ouvido o trecho anteriormente, o que é, porém, uma sensação diferente da primeira.

${ }^{15}$ Poderíamos encontrar em uma só canção $n$ fluxos se levássemos em consideração que o pulso sonoro também é fluxo.

16،“A principal diferença entre contraponto e harmonia está na ênfase. No contraponto, a melodia dá origem aos acordes, ou seja, os acordes são conseqüência da superposição das linhas melódicas. Na harmonia, os acordes ditam o movimento das linhas melódicas individuais." (CARVALHO, 2006: 49-50) 